\title{
A Three-Fold Model of Pedagogical Provision for English Integrative Learning Activity of First-Year Students of International Education Institute
}

\author{
Nataliya I. Zamerchenko (a), Anastasiya V. Tikhomirova (b), Andrej V. \\ Kuznetsov (c), Olga P. Bogatyreva (d), Andrej A. Bogatyrev*(e)
}

(a), (c), (e) Moscow Pedagogical State University (MPSU), Moscow, Russia, e-mail: ni.zamerchenko@mpgu.edu (b), (d) Tver State University (TSU), Tver, Russia, e-mail: innova86@mail.ru

\begin{abstract}
The purpose of the article is to describe the innovative theoretical communicator-centered triune model of an integrative approach towards organizing learning activities of first-year students of International Education department as one of the many possible productive models for vocationally oriented higher education training. The development of a theoretical model took into account the organizational, pedagogical, linguistic, linguodidactic and methodological aspects of its implementation. The key theoretical approach to solving the complex of objectives is based on modern understanding of the nature of professional pedagogical communication as distinguished by such traits as controllability, flexibility, interactivity, representativeness and interpretability, reflected in the adopted international 21st Century Skills Concept. The results of the study include the theoretical model, disclosed as a set of essential characteristics, the outline of the program of forming of a professionally-oriented linguistic personality, description of means of methodological support. The pilot experiment confirmed the productivity of the innovative teaching model. The practical significance of the research results is determined by the productivity of the proposed integrative threedimensional approach to the organization of the educational process in the context of international education in English.
\end{abstract}

Keywords: international education; integrative pedagogical model; innovative vocationally-oriented learning; EFL; CCLT.

(C) 2019 Nataliya I. Zamerchenko, Anastasiya V. Tikhomirova, Andrej V. Kuznetsov, Olga P. Bogatyreva, Andrej A. Bogatyrev

This is an open access article distributed under the terms of the Creative Commons Attribution License (CC BY 4.0), which permits unrestricted use, distribution, and reproduction in any medium, provided the original author and source are credited.

Published by Kazan Federal University and peer-reviewed under responsibility of IFTE-2019 (V International Forum on Teacher Education)

\footnotetext{
* Corresponding author. E-mail address: aa.bogatyrev@mpgu.edu
} 


\section{Introduction}

English is beyond any doubt the language of modern educational standards and academic research. Humanity faces a great demand for highly motivated teachers of English, possessing the 21st century skills (21st Century Skills Map 2011) and substantial vocational training. But theoretical knowledge is still not everything in future teachers' education. Beside good knowledge, one must possess a magic alloy of personal and professional qualities and attitudes, based on individual experience and communication practice to make a real teacher in real educational environment. The problem of the study is finding pedagogical means and ways of achieving integrity of educator's personality in modern international professional contexts. So we need a holistic model of teachers' education to provide new generation of learners with due educational guidance and assistance. This impetus to wholesome teaching has already evoked such powerful trends in education as Communicative language teaching (CLT) (Nunan, 2004, 6) and a 'dual focused' Content and language integrated learning (CLIL) (Coyle, Hood, \& Marsh, 2010). But preparing a teacher for international learners' audience still remains a challenging task to a degree. One is expected to make a merger of a person of education and knowledge, of inspiring pedagogic attitude and a skillful versatile interpersonal communicator in English. This desire for integrity in education is the key idea of our research, based on an attempt to synthesize CLT, CLIL and vocationalisation of pedagogical training for the Generation Next teachers.

The research is dedicated to developing such a system of communicator-centered support for a university student in the early stages of study, which will effectively contribute not only to achieving certain discrete subject-centered learning results, but will also contribute to vocational guidance in pedagogical training within frame of international education. It should be pinpointed from the very start that vocationalisation in education is not the same thing as just vocational training: "Vocationalisation refers to increasing the vocation oriented skills and components of all education for all students' (Akram, 2012, p. 144). It aims at giving learners confidence in one's educational and vocational development as a resource of personal growth and self-reliance. Here we see the problem of student's vocational identity and quality of education as two sides of the same coin. So education can be viewed as a process of vocational identity formation (cf. Wyszynska Johansson, Wärvik, \& Choy, 2018).

The goal of research is elaboration of theory and testing practical application of the new integrative model of vocationalisation of first-year Russian students of International Education department. The set of objectives includes:

1. designing a model, ensuring integration of education and 'vocationalisation' of graduate's personality;

2. modernization of the forms and content of education of a traditional university discipline;

3. elaboration of optimal learning environment and system of methodological support for vocational-oriented students' educational activities.

The purpose of the article is to describe the theoretical triune model of an integrative approach towards organizing learning activities of first-year students of International Education department as one of the many possible productive models for vocationally biased higher education training. The article also describes a system of methodological support of this innovative model.

The framework of interdisciplinary communicative paradigm required elaboration of a more complex learning model as compared with CLIL - Content and Language Integrated Learning. So CLIL model was enriched by developing the target focus on the vocationally-oriented development of the 
secondary language personality of the future teacher. The communicator (or 'linguistic personality' in Russian academic tradition) is the subject of communication, responsible for communicative event (Bogin, 1980). By contrast to CLIL and CLT this approach may be generally labelled as CCLT - communicator centered language teaching.

The three-fold integrative learning model comprises three interrelated student's immersion principles:

1. target language immersion;

2. subject of the study immersion (content, problematics, meta-language);

3. "vocationalisation" immersion in reversible pedagogical communication practices.

The last one denotes not just speaking English (1), but also mastering communicative roles, strategies, tactics and style of task-solving activity as well as developing critical thinking skills. It triggers English in use acquisition not only from the standpoint of a learner, but also from the standpoint of a researcher and teacher (3). So EFL communicative competence includes not only semantics (concerned with presentation of scientific information), but also pedagogical pragmatics, demanding special rhetoric and 'recipient design' to provide effectiveness of pedagogical communication.

One of the key focuses of the communicator-centered threefold model development is its interactivity. This one is multi-faceted and multi-level. It necessarily includes not only 'learner - content interaction' and 'learner - instructor' interaction, but also 'learner - learner' peer-students' interaction (cf. Moore, 1989, pp. 1-7).

The language objectives (1) may relate simply to communicating the content effectively, or they may include notions (such as specialist vocabulary from the unit) or functions (such as the ability to discuss effectively) or even be form-focused (for example, concerning effective use of the past tense).

The proposed communicator-centered threefold model seems to be close to so-called 'Specificdomain vocational CLIL' (or 'Model B5') (cf. Coyle, Hood, \& Marsh, 2010), dedicated to some 'specific task-based functions' acquired by learners of English. But still there is a difference in the hierarchy of focuses. It is not the merge of English language and educational content that is the main focus and objective of our model. It is the observation of integration of language and content skills within the scope of professional educational interaction concepts and skills of a future pedagogue. So the professional communicator focus foregrounds and occupies the superposition, preconditioning all possible personalitybased, language-based, content-based and inter-disciplinary connections.

\section{Methodology}

The theoretical approach to solving the complex of objectives is based on the understanding of the integrative nature of the teacher's linguistic personality in the context of professional linguodidactics. It assumes modern understanding of the nature of professional pedagogical communication as distinguished by such traits as controllability, flexibility, interactivity, representativeness and interpretability, reflected in the adopted international 21st Century Skills concept. The development of a theoretical model has been carried out within the framework of a humanistic and integrative approach in education. It took into account the organizational, pedagogical, linguistic, linguodidactic and methodological aspects of its implementation.

The investigation is based on deductive approach as well as on pedagogical design, while the main empirical method of the research is a pilot experiment, involving eighty students of MPSU 
International Education Institute.

The development of supportive methodology for the first-year students was performed on the basis of the 'Introduction to theoretical and applied linguistics' English course at International Education Institute of MPSU. The academic discipline chosen for pilot experiment was 'Introduction into theoretical and applied linguistics in English'. Why linguistics? Generally speaking, it might be another subject. However, linguistics has at least a few unarguable bonuses - such as unrestrained desire for unprejudiced and precise universal knowledge, deep interest in different cultures and languages of the world, smart communicative bias, function of universal methodology of humanities, systemic outlook, and yes - a strong English accent (William Jones, John Austin, John Searle, Herbert Paul Grice, Henry Widdowson etc.). Applied linguistics is also a growing field of merging mathematics, technology, sociology and humanities to design new solutions for education and social life. And last but not least - linguistics imparts the learners' sensitivity to invisible hand of culture in deeds of words.

\section{Research}

Elaboration of theoretical model was the first stage of study. Practical experimentation and verification of the model effectiveness was conducted in the last four months of 2018 on the base of International Education Institute of Moscow State Pedagogical University.

The experimentation part of research included three major stages. We distinguished passive, active and interactive levels of 'immersion in academic discourse'. The first stage of immersion reflects basic receptive educational skills (listening, reading texts and visuals) and reproductive (retelling) based on mnemonics, as well as on analytical note-taking. The second stage of immersion is based on the transactional model of gaining access to knowledge and referring it to the audience. The third stage exploits interactional model, which includes (3a) readiness for the synthesis of knowledge in interaction; (3b) managing the exchange of knowledge, assessments and conclusions in a dialogue, as well as creative synthesis of new scientific / educational information, based on the analysis of the arguments.

Taken this distinction into consideration, a "Four-Steps modular program" was developed to support vocationalisation of first-year International Education students (September to December 2018). It includes four interrelated modules, each characterized by a certain leading learning activity as a method of synthesizing and presenting essential educational information:

1. summarization;

2. analytical review;

3. presentation of a scientific concept;

4. grounded methodological discussion involving confrontation of different points of view.

The program contains a map of the evolution of students' educational practices and a transparent monitoring system, integrated with 'vocationalisation' scheme. Its critical thinking component develops meta-cognitive, meta-linguistic, meta-communicative and axiological reflection of students.

\section{III.a. Key methodological approaches in experimentation}

Communicative Language Teaching focus

Viewing Language as intersubjective meaning construction tool preconditioned priority of CLT approach to mastering English as educational tool. It admitted communicative task-based learning of necessary language and meta-language tools within context of educational activity, ensuing involvement of students in academic communication on the one side and vast application of interactive exercises and tests 
on the other. As a result, the performance level of individual student was judged both as (appropriate or not) interaction units (or communicative events) and (correct or not) instances (occurrences) of speaking English. The first-year students were trained to critique their peers (playing the role of students as teachers) from vocational point of view in a constructive key. Through presenting practice and group (or intergroup) discussion the students worked together to improve educational speaking skills.

Methodological approach to teaching Russian students linguistics in English followed 5 key features of communicative task-based teaching, described by David Nunan (Nunan, 1991, p. 279), such as (1) interacting in target language, (2) authentic teaching resources, (3) tasks, (4) developing 'learning to learn' techniques and (5) powerful accent on the positive role of learner's personal experience. Somehow, the list of seventeen criteria of good learning task by Nunan (1989, pp. 139-140) was also used productively in designing tasks and in critical assessment of educational interaction (developing vocational critical thinking component).

All the three modes of communication, included into 21st Century Skills Map (2011, p. 2) were trained at 'Introduction to Theoretical and Applied Linguistics' classes within complex approach as interdependent values of presentational, interpersonal and interpretative. An essential and consistent collection of supportive interactive learning materials for developing English for Presentation skills (or (presentative mode') was deployed at support page https:/ap-support.jimdofree.com/presentation-tips/. The ingrate approach CLT was based on methodological base of the Communicative Quest idea, developed by the famous WebQuests innovator Bernie Dodge (1995) and A.V. Tikhomirova (2013; Tikhomirova, Bogatyrev, \& Bogatyreva, 2018).

As for the target lexis acquisition it was trained according to Anastasiya Tikhomirova Four steps and stages model of foreign wording acquisition, including semantization, validation, valorization and revalorization, but mainly on the second and the third stages (Tikhomirova, Bogatyreva, Bogatyrev, \& Zhuravleva, 2016).

\section{Practice-based introduction to vocational meta-language focus}

Developing meta-language knowledge and skills concerning both of linguistics and teaching methodology is part of the proposed three-fold communicator-centered integrative learning model. It is not only Educational Content and English Language based, but also multi-faceted Educational Activity based. This trait of the model may be attributed to multi-targeting, but it rather should be attributed to reciprocal elucidation principle since language does not only play the role of the key to educational content, but also to educational communication events, processes and procedures.

\section{III.b. Key methodological forms, tools and solutions}

There have been tested three major forms and directions of pedagogical CCLT supportive methodology development such as (A) Educational Presentation (B) Interactive Hot Spot learning activities, (C) Group and Intergroup Discussion.

\section{A. Educational Presentation}

This form is tightly connected to developing modern Presentation Skills. As Short (1993, p. 633) points out the so-called complications in assessing CLIL learning results, based on the necessity of choice 'between the language and content knowledge of the students'. In our case the main stress was laid on 'language in action', on appropriateness and functional style issues in Classroom English. As for the correctness of students' data analyses and presentation English, it was a matter of well in advance teacher's preview of educative materials, produced by students. The MS PowerPoint (also Adobe PDF) presentations 
had been checked beforehand from the point of view of their capacity of communicating the scientific and educational content correctly and effectively. This involved:

a. The theme of presentation and content choice consistency focus;

b. Special terminology and lexis focus (linguistic meta-language, 'word bank', 'phrase bank', grammar structures etc.);

c. Clarity of expression and consistency of academic discourse;

d. Actual learners' cognitive background focus;

e. General listeners' feedback and interactive checking points focus;

f. Rhetoric structures of the educational message focus;

g. Academic English functional style and speech etiquette focus;

h. Academic References and indication of other sources of information.

This list shows the merge of integrate goal-seeking text production activity, English and content skills in agreement with the general idea of the three-fold integrative communicator-centered learning model. The pragmatics of the educational presentation includes both illocutionary and perlocutionary effects, concerned with cognitive sets of learners. Although the pupils were to prepare all the topics for the exam on their own, the fellow-student presentations were considered quite a valuable source of educational information. So the learners asked questions to specify new educational information from students as teachers. This stipulated enhancement of cooperative learning style at classes.

One of most important aspects in developing teachers' vocational communication skills is interaction skills. This implies monitoring levels of interactivity of educational communication between students as learners and students as teachers. This aspect is viewed and assessed in terms of multi-level interactivity model (Bogatyrev, Tikhomirova, \& Bogatyreva, 2017). The aforementioned model distinguishes between such steps of interactive educational presentation design as (1) meaningful content focus, (2) message structure focus, (3) speaker personality and performance focus, (4) audience concern and discussion focus, (5) revalorization power focus.

Monitoring the process of Educational Communication as Content and Language Integrated Learning Educational Presentation performance and its reception by learners

Students as teachers practiced interviewing and testing their listeners ('students as learners') to specify the grade of educational impact of the presentation. In fact the latter one ranged widely from general topic of speech to precise definition of key notions and educational task-solving activity schemes, varying from 'just fun' to progress, precision and appropriate practical application of new knowledge and rules. This wide variety range reflected the difference between various teaching strategies and solutions. It proved the importance of pedagogical training for achieving vocational goals.

\section{Practicing Teaching in Styles approach in Educative Presentation}

Educational Presentation can be performed in the linguistics classroom as a traditional academic report genre or interactive discovery narrative genre. The inherent characteristics of the subject of study allowed a lot of task-based investigation of subject matter. For example, Georg Grotefend's decoding of old Persian writing system was based on a number of sources such as substantial interpretation hypothesis and mathematical calculation of the writing system type. As a consequence, different strips of information may be involved in organizing cooperative learning and intergroup information exchange as well as brainstorming activity. This cooperative learning approach allows application of various complex heuristic techniques to uncovering the world of applied linguistics. 


\section{Limitations of the Educational Presentation technique}

The experimentation elicited some limitations of inverted classroom educational presentations technique. Firstly, some students proved to be taking for granted every little piece of students as teachers presented information. This was mostly due to passive learner's position in educational environment. Some students were also a bit too much involved in the job of presenting their educational materials and didn't pay much attention to teacher's interventions, critical remarks and extra information on argumentative topics. Somehow such drawbacks were likely to be fixed in the course of general discussion. The most severe limitation for application of the method is concerned with the language in use practice. Talking English in the classroom and not using the terms, actual lexis and phrases from the bank of useful expressions undermines the foundations of approach. So it cannot be tolerated in any case within frame of the three-fold model of English integrative learning application.

Interactive provision elements of the new educational content presentation and demonstration as well as testing the audience was up to the students as teachers to choose and provide. It was usually a questionnaire at the end of presentation, included in the slides or an interactive LearningApps interactive module embedded in presentation. Most often such certain checking points were subsequently included also in the test in Moodle or LMS course management systems.

The teacher of linguistics had designed beforehand a number of LearningApps interactive exercises and tests, so that learners could practice interpreting, classifying, re-interpreting, arranging and rearranging multi-patterned clusters and sequences of Classroom English and Academic English phrases and speech moves in typical and contrasting pragmatic situations and meaningful contexts.

This practice must have added to taking students' as teachers presentation most seriously. Another point of better understanding new interactive teaching materials is collective interpretation of primary results, including brainstorming, explication of hidden rules and discussion.

\section{B. $\quad$ Interactive Hot Spot learning extra activities}

This form was used to fix the problem of time-management in the classroom, when there were too many students willing to present educational information in the naught of time. In fact it was an extra learning activity - usually a short (2-3 minutes) interactive quiz or test, presented on the screen and also accessible for students' mobile devices via QR-code access. This form of presentation of educational information control imparted some sense of excitement to the educational event.

The whole ensemble of teaching techniques and interactive educative instruments was targeted at development and support of self-motivated student. Interviewing the students elicited three key points of preference, concerning interactive educational materials (apart from specific content informativity). According to International Education students, a student would be grateful if the interactive modules are really (a) bootstrapping (sparkling desire to talk English), (b) replayable, (c) recyclable. The latter two qualities mean capacity either to be used for a number of different purposes or to be further developed, modified and adjusted.

One of most productive technological solutions was designing a cascade of interconnected interactive modules (exercises or texts), proposed by Tikhomirova. This is essentially a set of interactive tasks building one on another, revealing multifarious interconnections and interdependencies between words, utterances, actions, attitudes, statuses, positions and roles in social interaction. On the other hand, students as teachers also made interactive exercises and tests to train target skills and check new knowledges. These provided expedient extra training facilities as well as monitoring tools for educational 
presentations.

C. Group and Intergroup Discussion

Another form of involving students into educational content English discussion and exchange of educational information and personal opinions was a list of debatable / argumentative questions for group and inter-group competitive discussion.

Here are a few sample topics for learners' grounded discussion:

"What are the five most influential languages in the modern world?"

"If you just could acquire another one language speaking skills without any effort, which one would you choose?"

"What kind of language (artificial or natural) is likely to make the language of the future century in our planet?"

"What writing system is likely to persevere best in the next thousand years?"

"If you were to add just another one function of language to those six, described by Roman Jackobson, which one would it be?"

"What function of language deserves most of all the name of educational function?"

This form (Intergroup Discussion) involved a good deal of preparatory homework, including data collection, information processing and intensive exchange of information within micro-groups of learners, working out the formulation of the thesis. It also demanded division and delegation of roles to different members of the group. A special emphasis was laid upon providing strict rules of interpersonal and intergroup discussion and English standard phrases support for expressing opinions, attitudes and assessment of the arguments of the parties. It was a special task and effort to activate useful English expressions and avoid lack of linguistic variety for the purpose of discussion. So the students were first asked to do specially-designed set of interactive tasks on LearningApps.org platform and then invited to choose useful phrases from the list of new expressions. The strength of (Inter)group Discussion form lies in its making the 'dialog-based level of interactivity' attainable (Komina, Tikhomirova, Bogatyrev, \& Bogatyreva, 2018, p. 841). The limitations of this form are predetermined by plenty of preparatory work the teacher must do to organize and guide a good substantial discussion and not to admit an exchange of ignorance.

\section{III.c. Communicator-centered three-fold English integrative learning model description}

The methodological peculiarities of the three-fold model of pedagogical provision for English integrative learning activity are as follows.

1. Task-centered meaningful English interpersonal and intergroup communication activity both in productive and receptive regimes.

2. Processing gobbets of useful information in Micro-groups (student-peer interaction).

$3 . \quad$ Cooperative learning.

4. Team effort approach in dealing with tasks, concerning data collection, data analysis, interpretation and representation of research results.

5. Group discussion and elaboration of assessment procedures.

6. Students' involvement in real life interpersonal and intergroup verbal negotiation for meaning.

7. Negotiating for meaningful information (student - teacher and student to student peer interaction). 
8. Co-creation of new educational information and shared meanings.

9. Developing rhetoric skills.

10. Reciprocal (peer-to-peer) task-based teaching and learning.

11. Developing monitoring and mutual assessment both 'from the learners' point of view' and 'from the teachers' point of view'.

12. Full-fledged role-playing performance of communicative mission.

13. Switching the roles of educational information producers, managers, interpreters, experts and consumers.

14. Development of reflective abilities and skills in educational and vocational contexts.

Vocationalisation immersion and involvement include Four Strategic Components:

A. 'Learning to speak' component (e.g. Classroom English, Academic English, English for Presentation, English for Discussion, English discourse markers application etc.)

B. 'Learning to learn' component (e.g. mastering various learning techniques and strategies)

C. 'Content-based learning to learn' component (e.g. application of commutation test or Greenberg's square etc.)

D. 'Learning to teach' component (e.g. application of problem-based narrative, task-based teaching techniques, designing and applying digital interactive teaching tools and visualization etc.)

E.

\section{Results}

The pedagogical experimentation confirmed that the use of a three-fold model of engaging a student in academic discourse contributes to the development of the student's active educational position, motivates 'vocationalisation', contributes to the formation of such professional qualities as critical thinking, responsibility and self-organization.

Eighty percent of students showed progress in terms of five clusters of skills, taken as indicators. Here is a list of particular indicators of positive results of practical application of the deductive model.

1. Developing Cooperative attitude to teaching events and teaching materials.

2. Developing Positive attitude to vocational criticism.

3. Developing Vocational Reflective skills

4. Developing Self-concept in vocational prospect.

5. Conditioning better English wording acquisition in multifarious subject matter and interdisciplinary contexts.

6.

\section{Discussions}

The proposed three-fold communicator-centered integrative learning model is an attempt to overcome difficulties, connected not only with formal educational outcomes, but also with vocational and educational motivation. General interviewing the students at the end of the first semester elicited assessment of 'Introduction into theoretical and applied linguistics' course as a most difficult though most challenging, new and wholesome as well.

Part of the program design was a map of the evolution of students' educational practices and a transparent monitoring system, integrated with 'vocationalisation' scheme. It was designed to follow students' developments in meta-cognitive, meta-linguistic, meta-communicative and axiological reflection of students. The achievements of students in task-solving and expressing their ideas in the classroom had 
been accurately fixed. This fixation reflected substantial growth of vocational self-consciousness and critical thinking skills as well as academic performance skills in $80 \%$ of students.

Nevertheless, some students would ignore the basic sets of the experimental course and didn't pay much attention to its integrative nature. Such students didn't do their home tasks fully, generally labelling them as too difficult, too time-consuming and demanding high level of English skills. In fact they took part in interactive training and other classroom activities willingly, but failed to consolidate new skills at home. This may be accounted for many reasons. One of the reasons, accounting for that fact may be general unpreparedness of some first-year students to identify oneself with future profession to be compared to senior students 'with broad range of experiences' (cf. Wyszynska Johansson, Wärvik, \& Choy, 2018). Another reason may be labelled as specific post-postmodern sensitivity (Petrouchko \& Bogatyrev, 2017). Yet another one reason is side effects of teaching extra-large groups. These and other challenges may be answered in the course of further development of supportive teaching methodology within proposed model.

\section{Conclusion}

The proposed three-fold communicator-centered integrative learning model contributes to advantage of communicative approach in education. It emphasizes understanding education as a strategically designed communicative system of teaching activity and learning events. It also lays strong accent on developing vocational and interdisciplinary reflective skills, grounding critical thinking application in practical educational and vocational context. The latter is viewed as a valuable source of vocationalisation of training future teachers and educators.

The model includes switching (constant rotation) of three meaningful positions within educational activity - those of learner, teacher and expert. This implies eliciting teaching and learning strategies as part of educational events and process. The acquired multi-faceted transparency of pedagogical communication provokes critical reflective approach and stipulates vocational responsibility of the future teachers.

The pedagogical pilot experiment confirmed that the use of a communicator-centered three-fold model of engaging a student in academic discourse contributes to the development of the student's active educational position, motivates 'vocationalisation', contributes to forming and developing such professionally significant personal qualities as vocational consciousness, critical thinking, responsibility, self-organization and self-reliance in professional contexts.

\section{Practical implications of the study}

The effectiveness of the three-fold model of pedagogical provision for English integrative learning activity of first-year students of pedagogical department is based not only on delegation of roles and statuses and fulfillment of the four-step engagement of students in educational activity in English, but also on an ensemble of supportive interactional environment, teaching tools, methodology and techniques. Such educational forms and techniques as 'Interactive Educational Presentation', 'Interactive Hot Spot' and 'Group and Intergroup Discussion' are not only directed at engaging students to produce teaching tools and at immediate monitoring of the quality of students' educational outcomes, but also at developing critical thinking skills both in subject content and vocational educational contexts. A teacher should allot enough time for discussion and criticism ensuing direct application of these educational techniques. Group method is also used to cope with multi-levels problem and to reduce the level of anxiety and alienation of disadvantaged students, experiencing difficulties with fluency in English or large new educational material portions. 


\section{References}

21st Century Skills Map (2011). Retrieved from: https://www.actfl.org/sites/default/files/CAEP/AppendixCAlignmentFramework21stCentury.pdf $03 / 11$

Akram, M. (2012). Formal Education, Skill Development and Vocationalisation: The Missing Link in India. Research on Humanities and Social Sciences, 2(8), 142-47.

Bogin, G. I. (1980). Sovremennaya lingvodidaktika [Modern linguodidactics]. Kalinin: KSU.

Bogatyrev, A. A., Tikhomirova, A. V., \& Bogatyreva, O. P. (2017). Interactivity levels of pedagogic presentation text formation. Mir lingvistiki i kommunikacii: elektronnyj nauchnyj zhurnal, 1(47), 45-58. Retrieved from: http://tverlingua.ru/archive/047/04_47.pdf

Coyle, D., Hood, P., \& Marsh, D. (2010). CLIL: Content and Language Integrated Learning. Cambridge: Cambridge University Press.

Dodge, B. (1995). WebQuests: A Technique for Internet-Based Learning. Distance Educator, 1(2), 10-13.

Komina, N., Tikhomirova, A., Bogatyrev, A., \& Bogatyreva, O. (2018). Interactive $\quad$ teaching foreign language communication in multi-level classroom in non-linguistic university. 18th PCFS 2018 - Professional Culture of the Specialist of the Future. The European Proceedings of Social and Behavioural Sciences EpSBS. Future Academy (ISSN 2357-1330). Retrieved from: https://www.futureacademy.org.uk/files/images/upload/18thPCSF2018F091.pdf

Moore, M. G. (1989). Editorial: Three types of interaction. The American Journal of Distance Education, 3(2), 1-7. doi:10.1080/08923648909526659

Nunan, D. (1989). Designing Tasks for the Communicative Classroom. Cambridge: Cambridge University Press.

Nunan, D. (1991). Communicative tasks and the language curriculum, TESOL Quarterly, 25(2), 279-295.

Nunan, D. (2004). Task-based language teaching. Cambridge: Cambridge University Press.

Petrouchko, I. A., \& Bogatyrev, A. A. (2017). Modern Christian Orthodox Preacher as Social Communicator Concept (A tentative model of linguistic personality of a preacher in educational context). Proceedings of the 7th International Scientific and Practical Conference "Current Issues of Linguistics and Didactics: The Interdisciplinary Approach in Humanities" (CILDIAH 2017) (pp. 226-232). Retrieved from: https://download.atlantis-press.com/proceedings/cildiah$17 / 25886106$

Short, D. (1993). Assessing integrated language and content instruction, TESOL Quarterly, 27(4), 627-656. Tikhomirova, A.V. (2013). Communicative quest as a prototype of a modern educational program on foreign language in a non-lingual university. In V. V. Pavlov (Eds.), Problems Of Modern Pedagogics in The Context Of International Educational Standards Development Materials digest of the XL International Research and Practice Conference and I stage of the Championship in Pedagogical sciences (pp. 82-84).

Tikhomirova, A. V., Bogatyreva, O. P., Bogatyrev, A. A., \& Zhuravleva, T. A. (2016) Key linguodidactic steps and stages of FL wording acquisition. Russian Linguistic Bulletin, 2(6), 115-116. Retrieved from:

https://www.researchgate.net/publication/307660237_KEY_LINGUODIDACTIC_STEPS_AND_ STAGES_OF_FL_WORDING_ACQUISITION 
Tikhomirova, A. V., Bogatyrev, A. A., \& Bogatyreva, O. P. (2018).Communicative Quest as an innovative EFL teaching technology. Modern Journal of Language Teaching Methods, 8(6), 147-158. Retrieved from: http://mjltm.org/article-1-124-en.pdf

Wyszynska Johansson M., Wärvik G-B., \& Choy, S. (2018). Vocationalising Specialized Concepts: Appropriating Meanings Through Feedback, Vocations and Learning, 1-19. Retrieved from: https://doi.org/10.1007/s12186-018-9204-4 